\title{
Risk Factors for Depression and Anxiety Disorders Among Bangladeshi Dental Students: A Cross-Sectional Survey Study
}

\author{
Md. Omar Faruk 1,2 (D) Mohammed A. Mamun ${ }^{1,3}$ (D) Abu Bakkar Siddique ${ }^{1,3}$ (D) \\ Mark D. Griffiths ${ }^{4}$ iD
}

Accepted: 6 July 2021

(c) The Author(s) 2021

\begin{abstract}
Dental students are highly prone to mental health suffering due to the stressors related to their educational, academic, and clinical environment. However, there are no previous studies that evaluated the mental health problems among dental students in Bangladesh. Therefore, the present study assessed the prevalence of depression and anxiety and its covariates. A cross-sectional survey was carried out among the students of five (out of a total of nine) Bangladeshi public dental institutes. The survey included the Patient Health Questionnaire, the Generalized Anxiety Disorder scale, and questions relating to sociodemographic factors, personal suffering, and family mental health history. Results indicated that the prevalence rates for moderate to severe depression and anxiety were $27.4 \%$ and $18.2 \%$, respectively. The risk factors for depression and anxiety were being female, coming from city areas, having past-year psychological and physical suffering, having past-year traumatic events, and having a family history of mental illness, as well as a range of suicide-related behaviors. The prevalence rates of depression and anxiety in the present study were relatively lower than other dental student cohorts residing outside Bangladesh. Further investigations are suggested based on the limitations and strengths of the present study.
\end{abstract}

Keywords Depression · Anxiety · Dental students $\cdot$ Prevalence and risk factors $\cdot$ Family mental history $\cdot$ Bangladesh

Mark D. Griffiths

mark.griffiths@ntu.ac.uk

Md. Omar Faruk

omarfaruk.alfurkan@gmail.com

Mohammed A. Mamun

mamunphi46@gmail.com

Abu Bakkar Siddique

abubakkarsamrat1010@gmail.com

1 CHINTA Research Bangladesh (Centre for Health Innovation, Networking, Training, Action and Research - Bangladesh), Savar, Dhaka, Bangladesh

2 Bachelors of Dental Surgery, Dhaka Dental College, Dhaka, Bangladesh

3 Department of Public Health and Informatics, Jahangirnagar University, Savar, Dhaka, Bangladesh

4 Psychology Department, Nottingham Trent University, Nottingham NG1 4FQ, UK 
Achieving a degree from the healthcare institutes (i.e., medical science, dental science etc.) is highly prestigious and among the most sought-after academic degrees worldwide. Becoming a healthcare professional can provide life security and have additional earning opportunities compared to other professions. Of the healthcare professions, dental surgeons rank as the fifth most demanding profession globally (Theodorou, 2019). In attempting to at securing such a life, the profession has highly competitive examinations as a pre-requisite to enroll on such degrees globally. In Bangladesh (where the present study was carried out), undergraduate dental science is commonly known as a Bachelor of Dental Surgery (BDS) and only permits approximately $2-3 \%$ of the total students applying to enroll in government institutes that host such courses.

Although enrolling in dental colleges is highly competitive in the Bangladeshi education system and the resultant job is among the most prestigious globally, job security in the profession is still uncertain in Bangladesh (Rahman, 2015). In Bangladesh, for completing the dental degree, students have to complete many of the courses that are required for a medical degree, but dental graduates are not permitted to practice except for dental and maxillofacial treatments. Moreover, although dental graduates read basic medical courses (e.g., anatomy, physiology, biochemistry, pathology, pharmacology, immunology, microbiology etc.), they are restricted in pursuing postgraduate degrees in these subjects (MPhil, $\mathrm{PhD}$, etc.). Additionally, the typical job sectors of a dental surgeon are not well-established in Bangladesh (i.e., practicing dental and maxillofacial-related treatments). The Bangladesh Civil Service (BCS Health) provides the only Bangladeshi government jobs for dental surgeons. In addition, there is restricted scope for non-government jobs for dental graduates in Bangladesh (Rahman, 2015).

Given this background, it is suspected that dental students may suffer from common mental health problems. Previously, many global studies concerning the psychological wellbeing of dental students have been carried out (e.g., Basudan et al., 2017; Naz et al., 2017; Newbury-Birch et al., 2002; Radeef \& Faisal, 2018; Vergara et al., 2013) but no previous study has ever been conducted in Bangladesh. Recent systematic reviews of global studies identified the common mental disorders among medical students and reported $33.8 \%$ for anxiety (95\% confidence interval: $29.2-38.7 \%$ ) and $27.2 \%$ for depression $(95 \%$ confidence interval: 24.7-29.9\%) (Quek et al., 2019; Rotenstein et al., 2016). Other studies have reported that the rates of anxiety and depression for North American medical students were $65.5 \%$ and $66.5 \%$, respectively (Hope \& Henderson, 2014), and the mean prevalence rate for anxiety and depression among medical students in China was $27.22 \%$ and $32.74 \%$, respectively (Mao et al., 2019). However, the most common mental health suffering includes depression, suicidality, stress, anxiety, and burnout (Basudan et al., 2017; Dyrbye et al., 2006). These disorders are also cited in approximately $90 \%$ of the global suicide cases (Fleischmann et al., 2005; Harris \& Barraclough, 1997; Mamun \& Griffiths, 2020). Among Bangladeshi medical sciences students, persistent academic pressure appears to be the most important proximal suicide risk factor (Mamun et al., 2020b), which has also been alluded to in the retrospective studies of university student suicide (Mamun et al., 2020c).

The World Health Organization (World Health Organization, 2017) classifies common mental disorders into two main diagnostic categories (i.e., depressive disorders and anxiety disorders), and these types of psychological suffering are highly prevalent across all age groups in the adult population. More than 300 million people suffer from depression globally, and the number of individuals with anxiety disorders is almost the same. Moreover, depression is the single leading contributor to global disability among all ages (7.5\%), whereas anxiety disorders are ranked sixth (3.4\%). Additionally, both conditions can be experienced together (i.e., simultaneous comorbidity) and can lead to suicide in some cases 
(World Health Organization, 2017). However, countries like Bangladesh appear to have less concern than others in investigating these common problems. Given that mental health issues among dental students have never been assessed in Bangladesh, there is a knowledge gap. The country's health policymakers need such information so that appropriate information for student mental health support programs can be given. Consequently, the objective of the present exploratory study was to assess the relationships between Bangladeshi dental students' mental health problems (i.e., depression and anxiety) and associated predictors (i.e., socio-demographic variables, personal suffering, family history related to mental health illness, etc.).

\section{Methods}

\section{Participants and Procedure}

Getting admission into a government dental college or dental unit (of a medical college) is seen as a gateway to success in Bangladesh, and the country has a total of nine public dental institutes. The present cross-sectional study was conducted among a convenience sample of the only public dental colleges $(n=1)$ and those higher education organizations that have dedicated dental units $(n=4)$ (i.e., Dhaka Dental College, Sir Salimullah Medical College Dental Unit, Shaheed Suhrawardy Medical College Dental Unit, Rajshahi Medical College Dental Unit, and Rangpur Medical College Dental Unit). A face-to-face survey was carried out from August to October 2019 in the student accommodation halls. The aim was to collect 500 participants based on the graded scale of sample sizes as recommended by Bujang et al. (2018), in which a sample size of 500 is considered very good. The research team approached almost 1000 students as possible during this period, and 487 students began the survey (i.e., response rate $48.7 \%$ ). After the removal of incomplete questionnaires, 468 of the sample remained for final analysis.

\section{Ethics}

This study was carried out adhering to the guidelines of medical research in the Helsinki Declaration, 1975. Additionally, the study protocol was approved by the ethics committee of the Institute of Allergy and Clinical Immunology of Bangladesh, Dhaka, Bangladesh (Ref: IRBIACIB/CEC/07201919/301). Informed written consent was taken from the participants before collecting the data. No financial gain was offered to the participants for taking part in the study. Anonymity and confidentiality were ensured for all participants during the entire study.

\section{Measures}

\section{Socio-Demographic Factors}

Data concerning socio-demographic factors were collected, including gender, institute location, year of study, permanent residence, religion, family type, family monthly income, cigarette smoking, and psychoactive substance use. Typically, Bangladeshi students prefer to study at an institute in Dhaka (because it is the most developed city in Bangladesh and 
has the most job opportunities); therefore, this study categorized the dental institutes into two types based on whether they were studying inside Dhaka (Dhaka Dental College, Sir Salimullah Medical College Dental Unit, and Shaheed Suhrawardy Medical College Dental Unit) or outside Dhaka (Rajshahi Medical College Dental Unit and Rangpur Medical College Dental Unit). Based on family monthly income, participants were divided into one of three socio-economic classes-lower class (less than 15,000 Bangladesh Taka [BDT]), middle class (15,000 to 30,000 BDT), and upper class (more than 30,000 BDT).

\section{Personal and Family History}

Other variables assessed in the study included questions relating to past-year physical illnesses, past-year mental health illness, past-year post-traumatic events, past-month suicidal ideation, past-month suicidal plans, past-month suicidal attempts, family mental illness history, family suicide attempt history, and family suicide history.

\section{Patient Health Questionnaire}

The 9-item Patient Health Questionnaire (PHQ-9) was used in the present study (Kroenke et al., 2001). The scale was developed to screen for depression in community and clinical settings based on the prior 14 days. Answers are provided using a four-point Likert scale $(0=$ not at all, $1=$ several days, $2=$ more than half of the days, and $3=$ nearly every day), leading to a score range of $0-27$, where a score of 0 indicates the absence of depression symptoms, and 27 indicates daily depressive symptoms. A score of $\geq 10$ was retained as indicating the presence of depression. This cut-off has previously shown an $88 \%$ sensitivity and $88 \%$ specificity for depression (Kroenke et al., 2001). In the present study, Cronbach's alpha was very good (0.897), as with the recent Bangladeshi studies using the scale (e.g., Bhuiyan et al., 2020; Hossain et al., 2019).

\section{Generalized Anxiety Disorder}

The 7-item Generalized Anxiety Disorder (GAD-7) scale was used in the present study (Spitzer et al., 2006). The scale was developed to screen for anxiety disorder based on the prior 14 days. Answers are provided on a four-point Likert scale $(0=$ not at all, $1=$ several days, $2=$ more than half of the days, and $3=$ nearly every day), leading to a score range of 0-21, where a score of 0 indicates the absence of anxiety symptoms, and 21 indicates daily anxiety symptoms. A score of $\geq 10$ was retained as indicating the presence of anxiety. This cut-off has previously shown an $89 \%$ sensitivity and $82 \%$ specificity for anxiety (Spitzer et al., 2006). In the present study, Cronbach's alpha was very good (0.896), as with the recent Bangladeshi studies using this scale (e.g., Bhuiyan et al., 2020; Hossain et al., 2019).

\section{Statistical Analysis}

Data were analyzed using the Statistical Package for Social Science (SPSS) version 22.0. Descriptive statistics (e.g., means, frequencies, percentages) and first-order analysis (chisquares, Fisher's exact tests) were carried out (and presented in the tables). Categorical variables were compared with depression and anxiety using the chi-square tests and Fisher's exact tests. For assessing the risk of associated variables, all significant variables 
in first-order analysis were entered into the binary logistic regression in both unadjusted and adjusted models with depression and anxiety as the dependent variables. The logistic regression was interpreted with $95 \%$ confidence intervals, and a $p$-value of $<0.05$ was considered as significant in the present study.

\section{Results}

\section{Characteristics of the Participants}

With the regard to socio-demographic variables, the majority of the students were female (76.3\%) and resided Inside Dhaka (65.5\%). Most participants were Muslim (88.5\%) and belonged to a nuclear family $(87.8 \%)$. Most were non-smokers $(95.7 \%)$ and non-psychoactive substance users (97.9\%) (Table 1). A small proportion of the sample suffered from past-year physical illness (12.8\%) and mental disorders (11.3\%), and 40.2\% reported experiencing past-year post-traumatic events. Moreover, $16.5 \%$ of participants reported a family history of mental illness, and 3.8\% reported at least one suicide in their family, and $6.0 \%$ reported a history of family suicide attempts. Finally, $12.4 \%, 2.6 \%$, and $1.1 \%$ of participants had past-month suicidal ideation, suicide plans, and suicide attempt, respectively (Table 2). The presence of moderate to severe depression and anxiety was reported to be $27.4 \%(n=128)$ and $18.2 \%(n=85)$, respectively (Fig. 1$)$.

\section{Variables Associated with Depression and Anxiety}

Results demonstrated that females were more prone to depression than males $(29.7 \%$ vs. $\left.19.8 \% ; \chi^{2}=4.153, p=0.042\right)$, but no significant association was found in regard to gender and anxiety $\left(19.6 \%\right.$ vs. $\left.13.5 \% ; \chi^{2}=2.116, p=0.146\right)$. Being raised in a city area (as opposed to being raised in an urban area) was highly associated with both depression and anxiety $\left(\chi^{2}=4.304, p=0.038\right.$ and $\chi^{2}=10.506, p<0.001$, respectively). Although the pastyear physical illness was not significantly associated with depression, it was highly associated with anxiety $\left(33.3 \%\right.$ vs. $\left.15.9 \% ; \chi^{2}=10.657, p<0.001\right)$. Past-year mental illness was associated with depression $\left(\chi^{2}=59.159, p<0.001\right)$ and anxiety $\left(\chi^{2}=43.211, p<0.001\right)$, and past-year post-traumatic events were also associated with depression $\left(\chi^{2}=77.362\right.$, $p<0.001)$ and anxiety $\left(\chi^{2}=68.555, p<0.001\right)$. Finally, participants with a family history of mental illness, suicide attempts, and completed suicides were also significantly prone to suffering from depression and anxiety (Table 2).

\section{Risk Factors of Dental Students' Depression}

From the binary logistic regression, the risk factors for depression were being female $(\mathrm{OR}=1.708,95 \% \mathrm{CI}=1.017-2.871, p=0.043)$, coming from city area $(\mathrm{OR}=1.546$, $95 \% \mathrm{CI}=1.023-2.336, p=0.039)$, having past-year psychological suffering $(\mathrm{OR}=9.148$, $95 \% \mathrm{CI}=4.816-17.378, p<0.001)$, having a family mental illness history $(\mathrm{OR}=2.208$, $95 \% \mathrm{CI}=1.328-3.673, p=0.002)$, having a family history of suicide (OR $=3.517,95 \%$ $\mathrm{CI}=1.356-9.122, p=0.01)$, having a history of family suicide attempts $(\mathrm{OR}=5.40$, 95\% $\mathrm{CI}=2.420-12.049, p<0.001)$, having past-month suicidal ideation $(\mathrm{OR}=8.131$, $95 \% \mathrm{CI}=4.444-14.878, p<0.001)$, having past-month suicide plans $(\mathrm{OR}=8.496,95 \%$ 
Table 1 Distribution of the socio-demographic variables with depression and anxiety

\begin{tabular}{|c|c|c|c|c|c|c|c|}
\hline \multirow[t]{2}{*}{ Variables } & \multirow[t]{2}{*}{ Total; $n(\%)$} & \multicolumn{3}{|c|}{ Depression $(128 ; 27.4 \%)$} & \multicolumn{3}{|c|}{ Anxiety $(85 ; 18.2 \%)$} \\
\hline & & Yes; $n(\%)$ & $\chi^{2}$ value & $p$ value & Yes; $n(\%)$ & $\chi^{2}$ value & $p$ value \\
\hline \multicolumn{8}{|l|}{ Gender } \\
\hline Female & $357 ; 76.3$ & $106 ; 29.7$ & 4.153 & 0.042 & $70 ; 19.6$ & 2.116 & 0.146 \\
\hline Male & $111 ; 23.7$ & $22 ; 19.8$ & & & $15 ; 13.5$ & & \\
\hline \multicolumn{8}{|c|}{ Institute location } \\
\hline Inside Dhaka & $307 ; 65.6$ & $89 ; 29.0$ & 1.208 & 0.272 & $62 ; 20.2$ & 2.482 & 0.115 \\
\hline Outside Dhaka & $161 ; 34.4$ & $39 ; 24.2$ & & & $23 ; 14.3$ & & \\
\hline \multicolumn{8}{|l|}{ Year of study } \\
\hline 4th year & $45 ; 9.6$ & $9 ; 20.0$ & 3.512 & 0.319 & $6 ; 13.3$ & 1.054 & 0.788 \\
\hline 3rd year & $180 ; 38.5$ & $57 ; 31.7$ & & & $34 ; 18.9$ & & \\
\hline 2nd year & $100 ; 21.4$ & $27 ; 27.0$ & & & $17 ; 17$ & & \\
\hline 1st year & $143 ; 30.6$ & $35 ; 24.5$ & & & $28 ; 19.6$ & & \\
\hline \multicolumn{8}{|c|}{ Permanent residence } \\
\hline Rural & $223 ; 47.6$ & $51 ; 22.9$ & 4.304 & 0.038 & $27 ; 12.1$ & 10.506 & $<0.001$ \\
\hline Urban & $245 ; 52.4$ & $77 ; 31.4$ & & & $58 ; 23.7$ & & \\
\hline \multicolumn{8}{|l|}{ Religion } \\
\hline Non-Muslim & $54 ; 11.5$ & $12 ; 22.2$ & 0.808 & 0.369 & $13 ; 24.1$ & 1.435 & 0.231 \\
\hline Muslim & $414 ; 88.5$ & $116 ; 28.0$ & & & $72 ; 17.4$ & & \\
\hline \multicolumn{8}{|l|}{ Family type } \\
\hline Joint & $56 ; 12.0$ & $14 ; 25.0$ & 0.186 & 0.667 & $15 ; 26.8$ & 3.149 & 0.076 \\
\hline Nuclear & $411 ; 87.8$ & $114 ; 27.7$ & & & $70 ; 17.0$ & & \\
\hline \multicolumn{8}{|c|}{ Family monthly income } \\
\hline Lower class & $102 ; 21.8$ & $27 ; 26.5$ & 3.922 & 0.141 & $15 ; 14.7$ & 5.943 & 0.051 \\
\hline Middle class & $198 ; 42.3$ & $63 ; 31.8$ & & & $46 ; 23.2$ & & \\
\hline Upper class & $168 ; 35.9$ & $38 ; 22.6$ & & & $24 ; 14.3$ & & \\
\hline \multicolumn{8}{|c|}{ Cigarette smoker } \\
\hline Yes & $20 ; 4.3$ & $6 ; 30.0$ & 0.074 & 0.789 & $6 ; 30.0$ & 1.970 & 0.160 \\
\hline No & $448 ; 95.7$ & $122 ; 27.2$ & & & $79 ; 17.6$ & & \\
\hline \multicolumn{8}{|c|}{ Psychoactive substance user } \\
\hline Yes & $9 ; 1.9$ & $2 ; 22.2$ & 0.124 & 0.725 & $3 ; 33.3$ & 1.411 & 0.235 \\
\hline No & $458 ; 97.9$ & $126 ; 27.5$ & & & $82 ; 17.9$ & & \\
\hline
\end{tabular}

$\mathrm{CI}=2.262-31.907, p<0.001)$, and having a past-month suicide attempt $(\mathrm{OR}=10.935$, 95\% CI $=1.212-98.786, p=0.033$ ) (Table 3).

\section{Risk Factors of Dental Students' Anxiety}

The risk factors for anxiety were coming from city area $(\mathrm{OR}=2.252,95 \% \mathrm{CI}=1.367-3.707$, $p<0.001$ ), belonging to a lower or middle class family compared to an upper class one $(\mathrm{OR}=1.816,95 \% \mathrm{CI}=1.054-3.127$ vs. $\mathrm{OR}=1.034,95 \% \mathrm{CI}=0.515-2.079 ; p=0.05)$, having past-year physical illness $(\mathrm{OR}=2.638,95 \% \mathrm{CI}=1.450-4.801, p<0.001)$, having past-year psychological suffering $(\mathrm{OR}=6.392,95 \% \mathrm{CI}=3.488-11.715, p<0.001)$, having a family mental illness history $(\mathrm{OR}=2.644,95 \% \mathrm{CI}=1.525-4.586, p<0.001)$, 
Table 2 Distribution of the personal and family history-related variables with depression and anxiety status

\begin{tabular}{|c|c|c|c|c|c|c|c|}
\hline \multirow[t]{2}{*}{ Variables } & \multirow[t]{2}{*}{ Total; $n(\%)$} & \multicolumn{3}{|c|}{ Depression $(128 ; 27.4 \%)$} & \multicolumn{3}{|c|}{ Anxiety $(85 ; 18.2 \%)$} \\
\hline & & $\overline{\text { Yes; } n(\%)}$ & $\chi^{2}$ value & $\overline{p \text { value }}$ & $\overline{\text { Yes; } n(\%)}$ & $\chi^{2}$ value & $\overline{p \text { value }}$ \\
\hline \multicolumn{8}{|c|}{ Past-year physical disease } \\
\hline Yes & $60 ; 12.8$ & $22 ; 36.7$ & 3.006 & 0.083 & $20 ; 33.3$ & 10.657 & $<0.001$ \\
\hline No & $408 ; 87.2$ & $106 ; 26.0$ & & & $65 ; 15.9$ & & \\
\hline \multicolumn{8}{|c|}{ Past-year psychological suffering } \\
\hline Yes & $53 ; 11.3$ & $38 ; 71.7$ & 59.159 & $<0.001$ & $27 ; 50.9$ & 43.211 & $<0.001$ \\
\hline No & $415 ; 88.7$ & $90 ; 21.7$ & & & $58 ; 14.0$ & & \\
\hline \multicolumn{8}{|c|}{ Past-year post-traumatic events } \\
\hline Yes & $188 ; 40.2$ & $93 ; 49.5$ & 77.362 & $<0.001$ & $68 ; 36.2$ & 68.555 & $<0.001$ \\
\hline No & $280 ; 59.8$ & $35 ; 12.5$ & & & $17 ; 6.1$ & & \\
\hline \multicolumn{8}{|c|}{ Past-month suicidal ideation } \\
\hline Yes & $58 ; 12.4$ & $40 ; 69.0$ & 57.702 & $<0.001$ & $31 ; 53.4$ & 55.458 & $<0.001$ \\
\hline No & $410 ; 87.6$ & $88 ; 21.5$ & & & $54 ; 13.2$ & & \\
\hline \multicolumn{8}{|c|}{ Past-month suicide plan } \\
\hline Yes & $12 ; 2.6$ & $9 ; 75.0$ & 14.020 & $<0.001$ & $8 ; 66.7$ & 19.494 & $<0.001$ \\
\hline No & $456 ; 97.4$ & $119 ; 26.2$ & & & $77 ; 16.9$ & & \\
\hline \multicolumn{8}{|c|}{ Past-month suicide attempt } \\
\hline Yes & $5 ; 1.1$ & $4 ; 80.0$ & 7.051 & $<0.001$ & $4 ; 80.0$ & 13.002 & $<0.001$ \\
\hline No & $463 ; 98.9$ & $124 ; 26.8$ & & & $81 ; 17.5$ & & \\
\hline \multicolumn{8}{|c|}{ Family mental illness history } \\
\hline Yes & $77 ; 16.5$ & $32 ; 41.6$ & 9.608 & $<0.001$ & $25 ; 32.5$ & 12.604 & $<0.001$ \\
\hline No & $390 ; 83.3$ & $95 ; 24.4$ & & & $60 ; 15.4$ & & \\
\hline \multicolumn{8}{|c|}{ Family suicide history } \\
\hline Yes & $18 ; 3.8$ & $10 ; 55.6$ & 7.495 & 0.006 & $9 ; 50.0$ & 12.766 & $<0.001$ \\
\hline No & $450 ; 96.2$ & $118 ; 26.2$ & & & $76 ; 16.9$ & & \\
\hline \multicolumn{8}{|c|}{ Family suicide attempt history } \\
\hline Yes & $28 ; 6.0$ & $18 ; 64.3$ & 20.447 & $<0.001$ & $14 ; 50.0$ & 20.310 & $<0.001$ \\
\hline No & $440 ; 94.0$ & $110 ; 25.0$ & & & $71 ; 16.1$ & & \\
\hline
\end{tabular}

having a family suicide history $(\mathrm{OR}=4.921,95 \% \mathrm{CI}=1.891-12.805, p<0.001)$, having a family suicide attempt history $(\mathrm{OR}=5.197,95 \% \mathrm{CI}=2.375-11.373, p<0.001)$, having past-month suicidal ideation $(\mathrm{OR}=7.569,95 \% \mathrm{CI}=4.196-13.655, p<0.001)$, having past-month suicide plans $(\mathrm{OR}=9.844,95 \% \mathrm{CI}=2.892-33.510, p<0.001)$, and having a past-month suicide attempt $(\mathrm{OR}=6.970,95 \% \mathrm{CI}=1.146-42.376, p=0.035)$ (Table 4).

\section{Discussion}

The present study is the first to examine mental health illness among Bangladeshi dental students and found that the prevalence rates for depression and anxiety were $27.4 \%$ and $18.2 \%$ respectively. There are no prior Bangladeshi studies examining dental students' mental health. However, prevalence rates of $54.3 \%$ and $64.8 \%$ for depression and anxiety were reported among public medical students in a previous Bangladeshi study (Alim et al., 


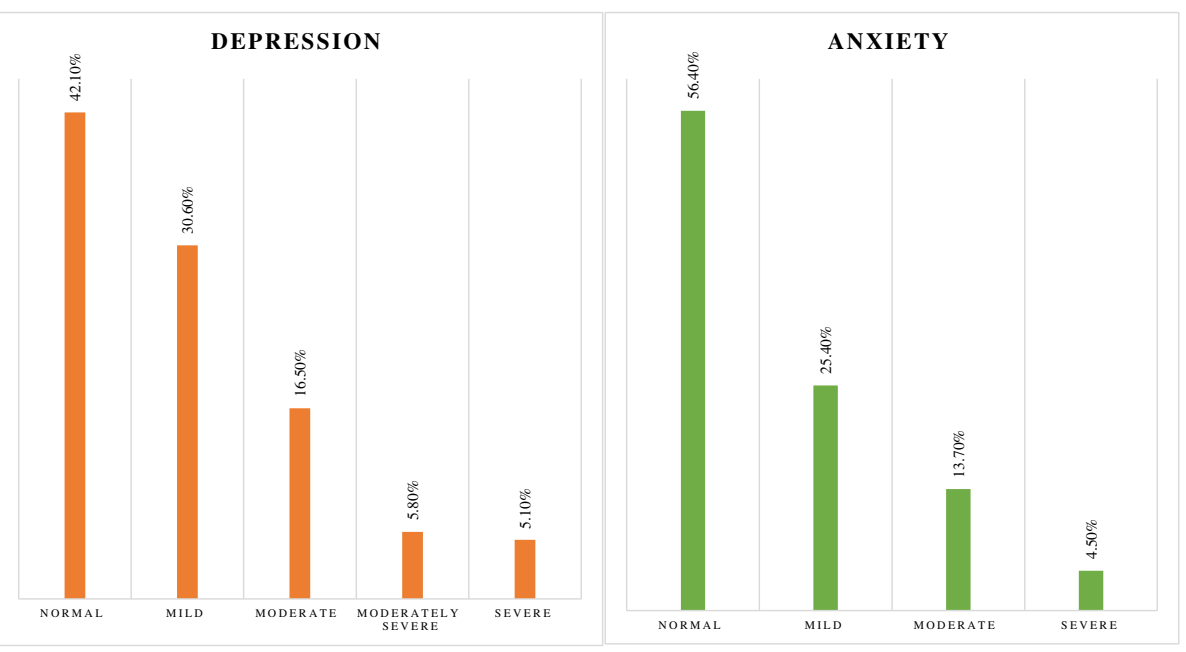

Fig. 1 Distribution of the depression and anxiety levels

2017). Other studies assessing related cohorts have also reported higher levels of depression and anxiety, including university students in general (Hossain et al., 2019; Mamun et al., 2019; Sakib et al., 2021) and unemployed graduates (Mamun et al., 2020a). However, the rate of depression in the present study (27.4\%) is similar to that of a recent largescale study among Bangladeshi students at the University of Dhaka (28.7\%; Rasheduzzaman et al., 2021).

Outside of Bangladesh, studies investigating depression and anxiety among dental students have reported heterogeneous rates in India [19.91\% depression; Reddy et al. (2013)], Pakistan [31\% and 41.9\%, respectively; Naz et al. (2017)], Malaysia [47.5\% and 67.3\%, respectively; Radeef and Faisal (2018)], Saudi Arabia [55.9\% and 66.8\%, respectively; Basudan et al. (2017)], and Colombia [56.6\% and 37.4\%, respectively; Vergara et al. (2013)]. However, a study in a UK dental school reported depression and anxiety rates of different year students; among second-year students, the prevalence rates for depression and anxiety were $15 \%$ and $47 \%$, among final year, the rates were $14 \%$ and $67 \%$, and among qualified dentists, the rates were $2 \%$ and $16 \%$ (Newbury-Birch et al., 2002). Therefore, it can be said that the prevalence rates of depression and anxiety among dental students in the present study appear to have a much lower prevalence than similar studies of dental students outside of Bangladesh.

Medical and dental students appear to be more prone to mental health problems compared to the other cohorts among this age group. The curriculum for dental and medical education can be highly stressful and can lead to mental health suffering for a minority of those studying. The major stressors relate to educational environment factors (i.e., curriculum design, performance expectation by the institution, performance results, limited leisure time, etc.), academic factors (i.e., work overload, overextended work, study pressure, study obligation, difficulty of classwork, peer competition, etc.), and clinical factors (i.e., learning clinical procedures, completion of a specified number of patient procedures coupled with attending lectures and studying for examinations require the dental students to work harder and longer and adding to the overall stress) (Alzahem, et al., 2011; Dyrbye et al., 2006; Rotenstein et al., 2016). 
Table 3 Logistic regression analysis of the variables with depression

\begin{tabular}{|c|c|c|c|c|c|c|}
\hline \multirow[t]{2}{*}{ Variables } & \multicolumn{3}{|c|}{ Unadjusted model } & \multicolumn{3}{|l|}{ Adjusted model } \\
\hline & Odds ratio & $\begin{array}{l}95 \% \text { confidence } \\
\text { interval }(\mathrm{CI})\end{array}$ & $p$ value & Adjusted odds ratio & $\begin{array}{l}95 \% \text { confidence } \\
\text { interval }(\mathrm{CI})\end{array}$ & $p$ value \\
\hline \multicolumn{7}{|l|}{ Gender } \\
\hline Female & 1.708 & $1.017-2.871$ & 0.043 & 1.491 & $0.808-2.750$ & 0.201 \\
\hline Male & Reference & & & Reference & & \\
\hline \multicolumn{7}{|c|}{ Permanent residence } \\
\hline Urban & 1.546 & $1.023-2.336$ & 0.039 & 1.160 & $0.711-1.893$ & 0.551 \\
\hline Rural & Reference & & & Reference & & \\
\hline \multicolumn{7}{|c|}{ Past-year psychological suffering } \\
\hline Yes & 9.148 & $4.816-17.378$ & $<0.001$ & 7.070 & $3.425-14.595$ & $<0.001$ \\
\hline No & Reference & & & Reference & & \\
\hline \multicolumn{7}{|c|}{ Past-month suicidal ideation } \\
\hline Yes & 8.131 & $4.444-14.878$ & $<0.001$ & 5.750 & $2.816-11.741$ & $<0.001$ \\
\hline No & Reference & & & Reference & & \\
\hline \multicolumn{7}{|c|}{ Past-month suicide plan } \\
\hline Yes & 8.496 & $2.262-31.907$ & $<0.001$ & 0.634 & $0.110-3.651$ & 0.610 \\
\hline No & Reference & & & Reference & & \\
\hline \multicolumn{7}{|c|}{ Past-month suicide attempt } \\
\hline Yes & 10.935 & $1.212-98.786$ & 0.033 & 3.703 & $0.242-56.754$ & 0.347 \\
\hline No & Reference & & & Reference & & \\
\hline \multicolumn{7}{|c|}{ Family mental illness history } \\
\hline Yes & 2.208 & $1.328-3.673$ & 0.002 & 0.872 & $0.441-1.725$ & 0.694 \\
\hline No & Reference & & & Reference & & \\
\hline \multicolumn{7}{|c|}{ Family suicide history } \\
\hline Yes & 3.517 & $1.356-9.122$ & 0.01 & 1.814 & $0.554-5.940$ & 0.325 \\
\hline No & Reference & & & Reference & & \\
\hline \multicolumn{7}{|c|}{ Family suicide attempt history } \\
\hline Yes & 5.40 & $2.420-12.049$ & $<0.001$ & 3.504 & $1.323-9.281$ & 0.012 \\
\hline No & Reference & & & Reference & & \\
\hline
\end{tabular}

Various physical and psychological signs and symptoms of engaging in such degrees can include worrying, tension, being upset, nervousness, discomfort, regret, lack of confidence, crying, indecision, unhappiness, avoidance, turmoil, insecurity, sadness, guilt, blame, irritability, apathy, weight loss, physical complaints, and fatigue (Alzahem et al., 2011) and these are common features associated with mental problems. However, the present sample reported lower than expected prevalence rates of depression and anxiety. This may be due to the participant selection criteria because only the renowned and older government (or public) dental institutes were considered in the present study, where participants may have had better academic facilities leading to chances of a more secure career (compared to dental colleges with a lesser reputation as well as some private colleges). Additionally, students from private dental institutes were not included in the present sample. These private institutes have high tuition fees, which may put additional stress on the family and can result in additional mental stress upon these students who feel obligated to do well for their families as well as themselves. In Bangladesh, dental patients prefer dental 
Table 4 Logistic regression analysis of the variables with anxiety

\begin{tabular}{|c|c|c|c|c|c|c|}
\hline \multirow[t]{2}{*}{ Variables } & \multicolumn{3}{|c|}{ Unadjusted model } & \multicolumn{3}{|l|}{ Adjusted model } \\
\hline & Odds ratio & $\begin{array}{l}95 \% \text { confi- } \\
\text { dence interval } \\
\text { (CI) }\end{array}$ & $p$ value & Adjusted odds ratio & $\begin{array}{l}95 \% \text { confi- } \\
\text { dence interval } \\
\text { (CI) }\end{array}$ & $p$ value \\
\hline \multicolumn{7}{|c|}{ Permanent residence } \\
\hline Urban & 2.252 & $1.367-3.707$ & $<0.001$ & 1.921 & $1.037-3.557$ & 0.038 \\
\hline Rural & Reference & & & Reference & & \\
\hline \multicolumn{7}{|c|}{ Family monthly income } \\
\hline Lower class & 1.034 & $0.515-2.079$ & 0.05 & 1.651 & $0.693-3.931$ & 0.080 \\
\hline Middle class & 1.816 & $1.054-3.127$ & & 2.047 & $1.095-3.828$ & \\
\hline Upper class & Reference & & & Reference & & \\
\hline \multicolumn{7}{|c|}{ Past-year physical disease } \\
\hline Yes & 2.638 & $1.450-4.801$ & $<0.001$ & 1.902 & $0.937-3.859$ & 0.075 \\
\hline No & Reference & & & Reference & & \\
\hline \multicolumn{7}{|c|}{ Past-year psychological sufferings } \\
\hline Yes & 6.392 & $3.488-11.715$ & $<0.001$ & 3.497 & $1.678-7.289$ & $<0.001$ \\
\hline No & Reference & & & Reference & & \\
\hline \multicolumn{7}{|c|}{ Past-month suicidal ideation } \\
\hline Yes & 7.569 & $4.196-13.655$ & $<0.001$ & 4.164 & $2.004-8.484$ & $<0.001$ \\
\hline No & Reference & & & Reference & & \\
\hline \multicolumn{7}{|c|}{ Past-month suicide plan } \\
\hline Yes & 9.844 & $2.892-33.510$ & $<0.001$ & 1.527 & $0.284-8.217$ & 0.622 \\
\hline No & Reference & & & Reference & & \\
\hline \multicolumn{7}{|c|}{ Past-month suicide attempt } \\
\hline Yes & 6.970 & $1.146-42.376$ & 0.035 & 1.381 & $0.105-18.207$ & 0.806 \\
\hline No & Reference & & & Reference & & \\
\hline \multicolumn{7}{|c|}{ Family mental illness history } \\
\hline Yes & 2.644 & $1.525-4.586$ & $<0.001$ & 1.064 & $0.514-2.202$ & 0.868 \\
\hline No & Reference & & & Reference & & \\
\hline \multicolumn{7}{|c|}{ Family suicide history } \\
\hline Yes & 4.921 & $1.891-12.805$ & $<0.001$ & 2.441 & $0.734-8.116$ & 0.146 \\
\hline No & Reference & & & Reference & & \\
\hline \multicolumn{7}{|c|}{ Family suicide attempt history } \\
\hline Yes & 5.197 & $2.375-11.373$ & $<0.001$ & 2.597 & $0.984-6.854$ & 0.054 \\
\hline No & Reference & & & Reference & & \\
\hline
\end{tabular}

treatment from those who graduated from a reputed public (rather than a private) dental college because dental students from private colleges tend to have less clinical experience (e.g., lack of seeing patients during internships) as well as less academic facilities (i.e., fewer laboratory facilities and instruments, etc.). These factors may also result in Bangladeshi private dental students being at higher risk of mental health suffering compared to public dental students. However, further studies are needed to be conducted with more rigorous sampling methods comparing dental students in private versus non-private institutes 
and investigating the effect of other academic-related contributing factors (e.g., educational environment, academic, clinical factors, etc.) upon dental students' common mental health problems (e.g., burnout, depression, stress, anxiety, psychological distress, etc.).

Among the present participants, those who came from a city area were more prone to mental health problems. Most of the previous Bangladeshi studies assessing students' cohorts have not reported such a relationship (e.g., Mamun et al., 2019), although one study among Bangladeshi students at the University of Dhaka reported similar findings (Rasheduzzaman et al., 2021). There is no explanation in the literature explaining why such a finding was found. It may be that students in the present study from city areas were more prone to depression and anxiety because students from city areas are typically better educated than students from villages and have higher expectations of getting into medical schools rather than dental schools. Those who fail to get into medical schools are likely to choose dental schools as the next "best" option, which may provide psychological uneasiness because they have not aspired to what they hoped to achieve. Students from villages may not have such expectations and be happier that they got into a dental school.

It is well-established that both fatal and non-fatal suicidal behaviors are consistently associated with family history-related factors (Wagner et al., 2003). A history of affective and antisocial disorders (e.g., schizophrenia, bipolar disorder, depression, etc.), parental separation, and family history of suicidal behavior and drug or substance abuse are more strongly associated with completed suicides than with other suicidal behaviors, but family systems problems (e.g., low cohesion and adaptability) and insecure parent-child attachments are more consistently associated with non-fatal suicidal symptoms than completed suicides (Wagner et al., 2003). Moreover, suicide and suicidal behaviors are highly associated with mental disorders, and it is estimated that over $90 \%$ of individuals who have committed suicide or have symptoms of suicidality have at least one mental disorder (Fleischmann et al., 2005; Harris \& Barraclough, 1997). Also, it is not surprising that mental disorders are consistently elevated among offspring of parents with any mental diagnosis. A recent meta-analysis reported anxiety disorders among the offspring of parents with schizophrenia, bipolar disorder, and depression (Rasic et al., 2013). It has also been found that having a family history of suicide and suicidal behaviors is also seen among offspring (Wagner et al., 2003). Similarly, a recent study among Bangladeshi university students found that there was an increased risk of depression due to family mental illness history (3.75 times increased risk), family suicide history (1.97 times increased risk), and family suicide attempt history (3.49 times increased risk) (Rasheduzzaman et al., 2021). As with these previous findings, the present study found that the participants with a family history related to mental health issues were most at risk of depression and anxiety.

Additionally, personal mental health suffering, including mood disorders, anxiety disorders, bipolar disorders, sleep problems, substance use disorders, etc. are the important risk factors for suicide completion, and as aforementioned, more than $90 \%$ of the suicide victims have at least one mental disorder (Fleischmann et al., 2005; Harris \& Barraclough, 1997). This is also reflected in the recent Bangladeshi studies assessing student mental health problems considering similar personal psychiatric suffering-related factors of the present study (see Rasheduzzaman et al. (2021) and Mamun et al. (2021) for details). More specifically, participants with a history of mental health problems had a five-fold increase in depression risk in Rasheduzzaman et al.'s study (2021) compared to a nine-fold increase for depression risk and a six-fold increase for anxiety risk in the present study. Similarly, $75.2 \%$ of participants who had engaged in suicidal behaviors were found to be depressed compared to $24.8 \%$ among those who had not engaged in suicidal behaviors (Sakib et al., 2021). These findings are consistent with the present findings. In addition to 
mental health-related issues, individuals with chronic health issues (i.e., angina, arthritis, bronchial asthma, hypertension, diabetes, hypothyroidism, etc.) can also be vulnerable to suicidal behaviors as well as mental illness (Moussavi et al., 2007; Rasheduzzaman et al., 2021). As with the previous studies (e.g., Rasheduzzaman et al., 2021; Sakib et al., 2021), personal suffering (i.e., past-year traumatic events, physical and psychological illness, and past-month suicidal behaviors) was highly associated with the dental students' depression and anxiety in the present study.

\section{Limitations and Conclusions}

The present study has a number of limitations. Given that the present study was a crosssectional survey study utilizing a convenience sample, it cannot address issues concerning causality, and the data are not necessarily representative of all Bangladeshi dental students. The self-selecting and self-report nature of the data is also subject to well-known methods biases that may have affected the study's findings (e.g., memory recall, social desirability, etc.). The present study only assessed public dental colleges. Therefore, the findings are limited in generalizing to private dental institutes, which may have also influenced the reported prevalence rates of depression and anxiety. Other factors that may have related to dental education were not considered in the present study (e.g., educational environmental, academic factors, clinical factors, etc.), and which may have also impacted the prevalence of mental health disorders (Alzahem et al., 2011; Sakib et al., 2021). These factors should be examined in future studies. Despite such limitations, the present study is the first to provide data concerning Bangladeshi dental students. The findings should help in healthrelated policymaking and facilitate further studies inside and outside Bangladesh among this cohort.

Acknowledgements The authors like to thank Tazkia Zaman Shova (Dhaka Dental College, Dhaka, Bangladesh) for her support in the project implications and data collection. It should also be noted that the authors' affiliation, the CHINTA Research Bangladesh, was formerly known as the Undergraduate Research Organization.

Author Contribution MAM planned the study; MOF implemented the study and collected the data; MOF and ABS entered the data, and analyzed it under MAM's guidance; MOF interpreted the analyzed data and drafted the manuscript under the supervision of MAM; MDG critically reviewed the draft along with extensive editing. All authors approved the final version of the manuscript.

\section{Declarations}

Ethics Approval All procedures performed in this study involving human participants were in accordance with the ethical standards of University's Research Ethics Board and with the 1975 Helsinki Declaration.

Consent to Participate Informed consent was obtained from all participants.

Conflict of Interest The authors declare no competing interests.

Open Access This article is licensed under a Creative Commons Attribution 4.0 International License, which permits use, sharing, adaptation, distribution and reproduction in any medium or format, as long as you give appropriate credit to the original author(s) and the source, provide a link to the Creative Commons licence, and indicate if changes were made. The images or other third party material in this article are included in the article's Creative Commons licence, unless indicated otherwise in a credit line to the 
material. If material is not included in the article's Creative Commons licence and your intended use is not permitted by statutory regulation or exceeds the permitted use, you will need to obtain permission directly from the copyright holder. To view a copy of this licence, visit http://creativecommons.org/licenses/by/4.0/.

\section{References}

Alim, S. M. A. H. M., Rabbani, M. G., Karim, E., Mullick, M. S. I., Al Mamun, A., \& Khan, M. Z. R. (2017). Assessment of depression, anxiety and stress among first year MBBS students of a public medical college, Bangladesh. Bangladesh Journal of Psychiatry, 29(1), 23-29. https://doi.org/10.3329/ bjpsy.v29i1.32748

Alzahem, A. M., van der Molen, H. T., Alaujan, A. H., Schmidt, H. G., \& Zamakhshary, M. H. (2011). Stress amongst dental students: A systematic review. European Journal of Dental Education, 15, 8-18. https://doi.org/10.1111/j.1600-0579.2010.00640.x

Basudan, S., Binanzan, N., \& Alhassan, A. (2017). Depression, anxiety and stress in dental students. International Journal of Medical Education, 8, 179-186.

Bhuiyan, M. A. H., Griffiths, M. D., \& Mamun, M. A. (2020). Depression literacy among Bangladeshi pre-university students: Differences based on gender, educational attainment, depression, and anxiety. Asian Journal of Psychiatry, 50, 101944. https://doi.org/10.1016/j.ajp.2020.101944

Bujang, M. A., Sa'at, N., \& Bakar, T. M. I. T. A. (2018). Sample size guidelines for logistic regression from observational studies with large population: Emphasis on the accuracy between statistics and parameters based on real life clinical data. Malaysian Journal of Medical Sciences, 25(4), 122-130.

Dyrbye, L. N., Thomas, M. R., \& Shanafelt, T. D. (2006). Systematic review of depression, anxiety, and other indicators of psychological distress among US and Canadian medical students. Academic Medicine, 81(4), 354-373. https://doi.org/10.1097/00001888-200604000-00009

Fleischmann, A., Bertolote, J. M., Belfer, M., \& Beautrais, A. (2005). Completed suicide and psychiatric diagnoses in young people: A critical examination of the evidence. American Journal of Orthopsychiatry, 75(4), 676-683. https://doi.org/10.1037/0002-9432.75.4.676

Harris, E. C., \& Barraclough, B. (1997). Suicide as an outcome for mental disorders. A meta-analysis. British Journal of Psychiatry, 170(3), 205-228. https://doi.org/10.1192/bjp.170.3.205

Hossain, S., Anjum, A., Uddin, M. E., Rahman, M. A., \& Hossain, M. F. (2019). Impacts of socio-cultural environment and lifestyle factors on the psychological health of university students in Bangladesh: A longitudinal study. Journal of Affective Disorders, 256, 393-403. https://doi.org/10.1016/j.jad.2019. 06.001

Hope, V., \& Henderson, M. (2014). Medical student depression, anxiety and distress outside North America: A systematic review. Medical Education, 48(10), 963-979. https://doi.org/10.1111/medu.12512

Kroenke, K., Spitzer, R. L., \& Williams, J. B. W. (2001). The PHQ-9: Validity of a brief depression severity measure. Journal of General Internal Medicine, 16(9), 606-613. https://doi.org/10.1046/j.1525-1497. 2001.016009606.x

Mamun, M. A., Akter, S., Hossain, I., Faisal, M., Rahman, M. A., Arefin, A., Khan, I., Hossain, L., Haque, M. A., Hossain, S., Hossain, M., Sikder, M. T., Kircaburun, K., \& Griffiths, M. D. (2020a). Financial threat, hardship and distress predict depression, anxiety and stress among the unemployed youths: A Bangladeshi multi-city study. Journal of Affective Disorders, 276, 1149-1158. https://doi.org/10. 1016/j.jad.2020.06.075

Mamun, M. A., \& Griffiths, M. (2020). A rare case of Bangladeshi student suicide by gunshot due to unusual multiple causalities. Asian Journal of Psychiatry, 49, 101951. https://doi.org/10.1016/j.ajp.2020. 101951

Mamun, M. A., Hossain, M. S., \& Griffiths, M. D. (2019). Mental health problems and associated predictors among Bangladeshi students. International Journal of Mental Health and Addiction. https://doi.org/10. 1007/s11469-019-00144-8

Mamun, M. A., Misti, J. M., \& Griffiths, M. D. (2020b). Suicide of Bangladeshi medical students: Risk factor trends based on Bangladeshi press reports. Asian Journal of Psychiatry, 48, 101905. https://doi.org/ 10.1016/j.ajp.2019.101905

Mamun, M. A., Misti, J. M., Hosen, I., \& al Mamun, F. (2021). Suicidal behaviors and university entrance test-related factors: A Bangladeshi exploratory study. Perspectives in Psychiatric Care. https://doi.org/ $10.1111 /$ ppc. 12783 
Mamun, M. A., Siddique, A. B., Sikder, M. T., \& Griffiths, M. D. (2020c). Student suicide risk and gender: A retrospective study from Bangladeshi press reports. International Journal of Mental Health and Addiction. https://doi.org/10.1007/s11469-020-00267-3

Mao, Y., Zhang, N., Liu, J., Zhu, B., He, R., \& Wang, X. (2019). A systematic review of depression and anxiety in medical students in China. BMC Medical Education, 19(1), 327. https://doi.org/10.1186/ s12909-019-1744-2

Moussavi, S., Chatterji, S., Verdes, E., Tandon, A., Patel, V., \& Ustun, B. (2007). Depression, chronic diseases, and decrements in health: Results from the World Health Surveys. The Lancet, 370(9590), 851858. https://doi.org/10.1016/S0140-6736(07)61415-9

Naz, N., Iqbal, S., \& Mahmood, A. (2017). Stress, anxiety and depression among the dental students of university college of medicine and dentistry Lahore, Pakistan. Pakistan Journal of Medical and Health Sciences, 11, 1277-1281. https://www.pjmhsonline.com/2017/oct_dec/pdf/1277.pdf

Newbury-Birch, D., Lowry, R. J., \& Kamali, F. (2002). The changing patterns of drinking, illicit drug use, stress, anxiety and depression in dental students in a UK dental school: A longitudinal study. British Dental Journal, 192(11), 646-649. https://doi.org/10.1038/sj.bdj.4801448

Quek, T. T., Tam, W. W., Tran, B. X., Zhang, M., Zhang, Z., Ho, C. S., \& Ho, R. C. (2019). The global prevalence of anxiety among medical students: A meta-analysis. International Journal of Environmental Research and Public Health, 16(15), 2735. https://doi.org/10.3390/ijerph16152735

Radeef, A. S., \& Faisal, G. G. (2018). Stressors and their association with symptoms of depression, anxiety and stress in dental students. Makara Journal of Health Research, 22(2), 58-62. https://doi.org/10. 7454/msk.v22i2.9064

Rahman, A. (2015). A few words for new dental surgeons (in Bangla). Retrieved November 16, 2019, from Platform website: https://www.cutt.ly/Ycmu4tI

Rasheduzzaman, M., al Mamun, F., Faruk, M. O., Hosen, I., \& Mamun, M. A. (2021). Depression in Bangladeshi university students: The role of sociodemographic, personal, and familial psychopathological factors. Perspectives in Psychiatric Care. https://doi.org/10.1111/ppc.12722

Rasic, D., Hajek, T., Alda, M., \& Uher, R. (2013). Risk of mental illness in offspring of parents with schizophrenia, bipolar disorder, and major depressive disorder: A meta-analysis of family high-risk studies. Schizophrenia Bulletin, 40(1), 28-38. https://doi.org/10.1093/schbul/sbt114

Reddy, V., Naveenm, N., Prabhu, M. S., Preethi, A., \& Ahmed, A. (2013). The evaluation of perceived stress and depression in dental undergraduates. International Dental Journal of Student Research, 1, 36-41. idjsr.com/uploads/21/1306_pdf.pdf

Rotenstein, L. S., Ramos, M. A., Torre, M., Segal, J. B., Peluso, M. J., Guille, C., Sen, S., \& Mata, D. A. (2016). Prevalence of depression, depressive symptoms, and suicidal ideation among medical students: A systematic review and meta-analysis. JAMA, 316(21), 2214-2236. https://doi.org/10.1001/jama. 2016.17324

Sakib, N., Islam, M., Al Habib, M. S., Bhuiyan, A., Alam, M. M., Tasneem, N., Hossain, M., Islam, S., Griffiths, M. D., \& Mamun, M. A. (2021). Depression and suicidality among Bangladeshi students: Subject selection reasons and learning environment as potential risk factors. Perspectives in Psychiatric Care, 57, 1150-1162. https://doi.org/10.1111/ppc.12670

Spitzer, R. L., Kroenke, K., Williams, J. B. W., \& Löwe, B. (2006). A brief measure for assessing generalized anxiety disorder: The GAD-7. Archives of Internal Medicine, 166(10), 1092-1097. https://doi.org/ 10.1001/archinte.166.10.1092

Theodorou, M. (2019). The 20 highest-paying jobs in the world. Retrieved November 16, 2019, from CareerAddict website: https://www.careeraddict.com/the-highest-paid-jobs-in-the-world

Vergara, K. A., Díaz Cárdenas, S., \& González Martínez, F. (2013). Symptoms of depression, anxiety and stress among dental students: Prevalence and related factors. Revista Colombiana De Psiquiatria, 42(2), 173-181. https://doi.org/10.1016/S0034-7450(13)70004-0

Wagner, B. M., Silverman, M. A. C., \& Martin, C. E. (2003). Family factors in youth suicidal behaviors. American Behavioral Scientist, 46(9), 1171-1191. https://doi.org/10.1177/0002764202250661

World Health Organization. (2017). Depression and other common mental disorders: Global health estimates. Retrieved November 16, 2019, from World Health Organization website: https://www.who.int/ mental_health/management/depression/prevalence_global_health_estimates/en/

Publisher's Note Springer Nature remains neutral with regard to jurisdictional claims in published maps and institutional affiliations. 